\title{
The vision of the Disney World: an experience marketing study at The Walt Disney Company
}

\author{
Rachel Farias do Patrocinio \\ Juliana Lopes de Almeida Souza \\ Carolina Toledo Oliveira Santos \\ Katheryne Soares Martins
}

\begin{abstract}
The article aims to understand through interviews with Disney park goers and prospects the strategies that the multinational company The Walt Disney Company uses to become a brand that enchants, using the so-called experience marketing. The project also looks at how The Walt Disney Company's strategies can influence not only customers but also prospects to trust and desire the brand. The survey pointed out that more than $90 \%$ of visitors had their expectations surpassed, even though they had a high level of expectation of knowing the parks.
\end{abstract}

Keywords: Disney; Marketing Services; Experience Marketing; Strategy; Positioning.

INTRODUCTION

The increasing competitiveness between companies brings out the need for them to stand out and differentiate themselves with consumers, since there are more options of consumption of the same product and service. According to Serasa Experian, in January 2017, 194,199 new companies were created in Brazil alone.

Experience marketing is a form of action for companies that want to present themselves in the market with a differential, working with what is relevant to their target customer / audience during their buying journey. Companies that engage in experience marketing can, in general, get good results from consumers. A great example of success in the area of experience marketing is The Walt Disney Company.

In a global annual report reviewing attractions by Themed Entertainment Association (TEA) and AECOM, one of the parks of The Walt Disney Company, Magic Kingdom appears as the world leader in visitations in the year 2016 with approximately 20,4 million visitors. The second, third and fourth place in the ranking is occupied by Epcot, Animal Kingdom and Hollywood Studios, which are also part of The Walt Disney Company. In its first half of 2016 release The Walt Disney Company reported a \$ 35 million increase over the same period last year, which totaled a profit of $\$ 2.1$ billion. Resort and resort revenue came to $\$ 3$ billion, reflecting public satisfaction with the brand's experience.

In recent years, many companies in Brazil have been engaged in marketing research and have sought seminars, workshops and lectures, since the practice of several well-applied marketing tools generate great returns to brands. Considering the importance of these investments in marketing, we carried out this work with the intention of exploring this scenario, pointing out the principles and strategies of a company that has already served as an example to boost several others and of several segments, whether small, medium or large. Through interviews 
with shoppers and prospects, the importance of the marketing principles and strategies used by The Walt Disney Company, a world reference in management, people management, business management and tourism, will be highlighted.

To have a strong brand in the market, marketing strategies need to be well aligned with the purpose of the company and what the company wants people to think about it. The entire strategy and management of marketing processes can lead to a business failure or success. Therefore, studying and understanding the strategies used by a company like The Walt Disney Company, with 93 years of market and reference in providing pleasant experiences to the customers, is of great importance.

The project will address and exemplify themes seen during the course of Advertising and Propaganda, and thus, will contribute to the training of group members. Disciplines such as Marketing Principles, Brand Management, Advertising and Propaganda Processes and Techniques, and Consumer Behavior will be addressed during the project. Thus, the authors of this project, as consumers of the brand, share a keen interest in understanding the strategies that have promoted the success of the Disney brand worldwide.

The project provides greater knowledge about marketing, business, consumer behavior, which is of great importance for the growth of any professional in the field. In this context, it is questioned: How does the Experience Marketing adopted by The Walt Disney Company influence customers and prospects? To build an argument, the research aims to analyze how the experience marketing adopted by The Walt Disney Company influences customers and prospects. The process of building the Disney brand is also analyzed as well as identifying the strategies used by Disney in building its marketing experience and also identifying how Disney's experience marketing influences customers and prospects.

\section{Branding: sets of techniques for building a brand}

Branding refers to the set of techniques and practices in the construction of a brand, which optimized become a competitive differential and encompasses everything that is associated with the brand. According to Keller and Machado (2007), the consumer can have a link with a brand and incorporate a deep meaning in it, offering their loyalty and trust that the brand will provide them with usefulness. Martins (2006) states that branded attitudes, when taken with knowledge and competence, can take the marks far beyond the economic nature, making them part of the culture and making them capable of directly influencing people's lives. Therefore, consider building a branding that is in accordance with the values of the brand and what the brand delivers, can delight the customer and make him give preference to everything that is related to his brand, always valuing the experience lived. Delivering positive consumer experiences ties the brand to the consumer's lifestyle, making buying attitudes a broader social context, says Hiller (2012, p.14). Aaker (2015) reports that understanding brands as assets, which have equity and strategy, has initiated drastic changes in perceptions about marketing and brand management. The companies that adopted and knew how to use this vision saw brand building move from the tactical and reactive to a crucial factor of business strategy. Aaker (2015) also points out the importance of building a brand personality because it establishes a connection with the consumer because it is defined as a set of human characteristics associated with the brand.

Positioning a brand is much more than targeting the selling product. When one thought of a brand, one used to think that having the same was the way a company had to get a job done, ie a reminder in the consumer's mind in a period of time where the main agent of the sale was the product. According to Costa (2013), the contingent, random character of individual contact 
with advertising in traditional media has changed: the passive recipient individual becomes an actor in a free cyberspace open to all possibilities, both for information and communication and for consumption.

The brand is much more of a property to have dominion or let the consumer be attentive to your product / service, but is everything that helps the customer to formulate an opinion about the company. The brand is the experience it causes on the customer, as he feels impacted on the conduct and actions of the same. Tangible things such as the presentation of a logo and a creative campaign today serve as a support for something greater, and what really make impact are the intangible elements, such as the fundamental words of the personality of the brand, the essence of the brand, which feelings the brand awakens. This creation most of the time gives a unique character to the same, with the personality it becomes differentiated.

Brand is much more than a communication campaign, it is as if it were a human being, having essence, values and personality. The process of creating a brand passes through 5 elementary processes, and these steps are important for a brand to be well structured. The first step is what it represents: being aware of the market and the context where the brand operates and its mission. The second is Storytelling. Where the customer will have an emotional connection with the brand. The third is the design: It makes the culture of all this experience, the company's operations, with business cards and web sites. The fourth component is its price, which is an expectation with the customer and establishes the brand value. The final component is the relationship: From Storytelling, the customer can feel empathy with the brand and make it close to it, making him want to be close to the brand. The relationship makes the customer feel special and part of something bigger.

Brand positioning is defined as the future form in which the target audience will recognize your brand. According to Serralvo and Furrier (2003, p. 2), "the value of a brand comes from its ability to gain exclusive, prominent and positive meaning in the minds of customers," that is, positioning requires that the choice of some aspect of the product / service delivered by the company is differentiated and more relevant than that of competitors.

A brand does not impose the positioning to its clients, it must plan and conquer the same, to the extent that the value that the public expects is delivered. It is necessary that the company has consistency and coherence in what it promises to deliver and in what it actually delivers, in order to position its brand, even before starting the positioning process, it will be necessary to know the brand and what is the what is the objective and in which sector / sectors she wants to differentiate herself. The positioning allows the brand to have a greater proximity to its target audience, because the thoughts and possible actions that must be taken will be identification points with the same. As an example, the positioning through benefits, where the brand brings its values added to the service / product and something more.

Choosing precisely on what level your brand wants to be is crucial, because having the best position means that the customer will remember the brand, for the unique service that the company provides. Over time these actions by positioning your brand, the continuity in segmenting and differentiating your products can bring the reach of leadership in the chosen category.

\section{Marketing 3.0: a new concept of experience}

Marketing 3.0 is known for the way it treats relationships between consumers, businesses and brands. Consumers have stopped being treated as a specific number of people and have come 
to be seen as individual beings, with their particularities and who mainly seek satisfaction in the purchase of products / services. Concern about making human need and feeling a sales strategy has grown over the last decade. An important competitive strategy is the deployment of Marketing 3.0. The meaning of this concept "has to do with emotional marketing, with marketing of the human spirit" (GOMES and KURY, 2013, p.5).

Customers have lost confidence in companies working with traditional marketing known as 1.0 marketing the focus was on the product. In Marketing 2.0 the focus was on the customer, with that there was no delivery of value. The consumer / individual feels the need to build relationships and not just to consume. Brands seek to establish a connection with consumers and this connection can be established through the integrity, image and identity of the same. These should be aware of concepts such as positioning, differentiation and the brand itself thus forming the authenticity of the essence of the company in the market. According to KOTLER (2010) "To establish a connection with humans, brands need to develop an authentic DNA, the nucleus of their true differentiation."

Marketing 3.0 seeks to provide sociocultural transformations, and for these transformations to occur the company must be aware of the need to develop a change of mission for it, and the way to do so is in the adoption of philanthropic actions and in the true support of good causes, clients value companies that also have cultural and social awareness. Marketing 3.0 also seeks to raise awareness about the humanization of processes, concern about how human feelings, social projects and their role in uniting and connecting people / individuals.

\section{Service Marketing}

Service marketing is a set of procedures to create, maintain and transfer value to customers. The marketing of services arose because of the high competitiveness in the market, because when it was sold something the same had its focus only in the products, that is, all the efforts of the marketing were directed to what was sold and not how it was sold. One of the characteristics of service marketing is its intangibility, it means that the service is something not palpable, it is a promise of something in which the buyer will only see the result after its completion. According to Cobra and Zwarg (1987) "A product is an object, something palpable, the service is the result of an effort, a performance. When the service is sold there is, as a rule, nothing to be shown that is tangible. Services are consumed, but they can not be possessed. "

Another feature of Service Marketing is inseparability, that is, production and consumption occur at the same time and you can not separate them. It is something heterogeneous, it is not something uniformly produced. The result of a service may not be the same every time it is rendered, even if it is done by the same person / company.

Marketing Services as well as Product Marketing has the "Marketintg Mix", better known as the 4 p's. People is the first $\mathrm{P}$ of the mix of services, covers those involved in providing the same, ie from the customer, some intermediary such as secretaries or others that may be in the middle, even the service provider itself. The second is the Profile / Square, this category includes the physical location where that service is provided. Then comes the $\mathrm{p}$ of Processes; encompasses the methodologies, the steps that will be taken for the consumer to have the service. And lastly in the Procedure, it involves the form of the relationship between the customer and this service provider, as will this procedure, as an example the decision of the service provider in deciding whether it will be the customer who will get that service or the same who goes to the client.

Service marketing has some peculiarities compared to marketing traditional products. Some of these challenges are linked precisely to the transmission of consumer confidence. Because the 
service is not tangible, this is a great challenge for service marketing, because it requires companies and providers to pay special attention. According to Cobra and Zwarg (1987) "The purpose of the service should always be the customer [...] it is not enough to sell a service, it is necessary to watch the client or the user so that he can have satisfaction with the sale or use of the service. service".

One of the ways to win the customer of a service is the experience you provide to him, having the greatest chance of becoming a loyal customer and possibly becoming a promoter or advocate.

\section{Product and Service Strategies}

One of the strategies that should be the focus of any company that wants to survive competitive markets. It is the differentiation of products and services. According to Grimm and Malschinger (2010), using this strategy, it is possible to create a unique identity to stand out in the market, through specific characteristics that will make the consumer differentiate his product with the one of the competition.

Cobra (2009, p.6) characterizes that "value is defined as the difference between what the customer expects and what he receives." By differentiating their product or service in the market, companies can assign values and benefits that make the difference to the consumer, in order to make them recognize value as a differential that impacts their purchase decision. It is to show the customer that when using your product or service, you will be acquiring something that no other offers, be it a tangible or intangible differential. Tigre, Audi and Brastemp are some examples of differentiation, as they attribute values to their products and are perceived differently from their competitors. The differentiation process is a challenge for all companies that want to operate in competitive markets. It is necessary to focus, and especially, the knowledge of strengths and weaknesses of your competitors, and thus define how to differentiate them, whether in price, design, ease of use, quality and durability of the product, after service sales, or any other characteristic that makes it better perceived by the consumer. But it is important not only to look at the physical aspects of the product but also to work on intangible values that can become differential and to connect the customer to your brand in a more special and lasting way.

The differentiation of products and services consists in finding out what the company can do that other companies are not doing. It is working to make your value proposition the heart of the brand and be perceived by your consumers and seen as a differential that makes you have a preference for your product or service.

\section{Marketing of experience: affective memory}

Experiential marketing or sensory marketing as it is also known, works with the client's emotional memory. Frederico Grosso says that customer experience involves "personalized content appropriate to the context in which the customer is inserted, presence in different points of contact and the interaction between them and the engagement with and between consumers" (GROSSO, 2016, p. 20).

In experience marketing the product / service that the brand offers must be a place where there is an immersion, a process so that the customer can experience the experience in a deep way and thus influence it to have a history with the brand. This positive experience can be passed on to other people. Experience is directly related to how your customer perceives your service as it has contact with your product / service and the brand, and how the customer 
perceives the values and the identity of the business. This is what Experience Marketing is all about, involving consumers in an unforgettable positive action for the consumer using one or all of the basic human senses such as smell, hearing, taste, touch and vision (LUÍS, 2014).

In the era of experiences / senses it is not enough to have a product / service of excellence, it is necessary to go beyond. The customer's perception of the difference between one brand and another is in adding detail, in the values that the brand wants to convey, working with the five senses of the consumer. The company needs to mark in people's hearts and minds. In order to have the basis of a differentiated company in the eyes of the customer, it is important to invest in professionals / employees and in their training, so that what the brand wishes to pass to the consumer is employed in a unified and linear way.

With the Cast Menbers policy adopted by Disney, the idea of transforming the common experience into the extraordinary experience the customer will have in the parks is the strongest pillar of the brand's marketing strategy and what helps it become an example of business conduct.

\section{THE WALT DISNEY COMPANY}

The Walt Disney Company is one of the most appreciated and successful companies worldwide and is a benchmark in management, marketing, business management, people management and tourism (EISNER, 2011). The name 'Disney' refers to magic, enchantment and imagination, and this is due to the strong organizational culture, based on the philosophy of the brothers Walter and Roy, who managed to fix the concept of "Disney magic" in people's minds. This concept persists to this day, being cultivated daily and is in everything that refers to the company.

According to Zenith Optmedia, The Walt Disney Company is the second largest media company in the world. The first place is Alphabet (Holding that commands Google) ${ }^{1 .}$

In addition to the theme parks and resorts, The Walt Disney Company operates in four major business areas: Cable TV Channels, Entertainment Studios, Consumer Products and Internet, and Direct Marketing. Brands like ESPN, Pixar, Marvel, ABC and Lucasfilm are also part of the organization. According to UNILUS Teaching and Research Magazine (2016, p.88), Disney considers the opinion of customers extremely important, because through the vision of each guest (as Disney calls its customers and visitors), it can generate improvements in planning and employee training. Therefore, the group has one of the biggest and best indicators of customer satisfaction in the world, with several listening posts spread across the parks, telemarketing service, interviews to verify the degree of satisfaction of the visitors and also through the guests themselves, who deal with services on a daily basis.

It all started with a man who dared to dream and make his dreams come true: Walt Disney. Walter Elias Disney was born on December 5, 1901, in Chicago, United States. At only 7 years old, Walt already revealed his talent for drawing. At the age of 16 , Walt joined the Red Cross and went to France, where he was an ambulance driver, shortly after World War I. At 18, Walt returned to Kansas and began his career as a cartoonist for advertisements and soon went on to produce animations for commercials that passed in the movies.

\footnotetext{
1 Disponível em: http://www.zenithoptimedia.cz/en/zenith/news/detail/102-Digital\%20gi. Acesso em 01 de
} Julho de 2017 
In 1923, decided to follow the career of animator, Walt Disney went to Hollywood, where he set up a small animation studio with his brother Roy. There were produced films where they used a technique that combined cartoon and real actors, and these were passed to the distributor M. J. Winkler.

In 1928, Walt Disney and an animator of his studio, Ub Iwerks, created the character who became Disney's greatest icon, Mickey Mouse. That same year, the character debuted in theaters with the short film 'Steamboat Willie', the first cartoon with soundtrack. The voice of the character was that of Walt Disney himself from 1928 until 1946. Mickey was so successful that in 1932 Walt Disney received a special Oscar for the creation of the character and in 1978 Mickey Mouse was the first cartoon character to receive a star on the sidewalk of Fame, in Hollywood, celebrating its 50th anniversary. ${ }^{2}$

Always innovating and bringing new, increasingly advanced technologies to make their stories come true, in 1932 Walt stunned the world with "Flowers and Trees," the first technicolor cartoon and the first to win the Oscar for "Best Short- Animation Footage '. In 1939, Walt proved that the animation was strong enough to be driven for something other than a short, and then created the first full-length animated feature film, 'Snow White and the Seven Dwarfs', which was a box office hit, and earned him the second Oscar award, given by Shirley Temple. The statuette was accompanied by 7 mini figurines, making reference to the film. In addition, 'Snow White and the Seven Dwarfs' is the first of many Disney Classics. Throughout his life, Walt Disney had 59 Oscar nominations, won 22 awards and received 4 honorary Oscars. That makes him the greatest record holder in Oscar history. The Walt Disney World is the largest and most famous theme park complex and the destination of millions of tourists from around the world who travel just to experience the Disney parks.

Disney's first theme park began to be planned in the 1950s. Walt Disney wanted to create a unique place where children and adults could experience unique experiences. So he had the idea to create something great, Disneyland. Walt bought 54 acres in California and on July 21, 1954 began, at an accelerated pace, the construction of the world's first theme park. Walt participated in all the planning of the park along with the most creative talents and went on to call them 'Image Keepers'3.

Disney decided that all the attractions of the park should be distributed from a central point, and with the recent success of 'Snow White and the Seven Dwarfs', this attraction should be a castle. The park's toys would be inspired by the Disney movies. On July 17, 1955, the park was inaugurated and the event was broadcast live on American TV's ABC network. For the inauguration, 11 thousand tickets were distributed to journalists and guests, but there were falsification of tickets and appeared more than 30 thousand people, which made it a real disaster. The whole structure of the park was not enough for such a large number of people. A few weeks later, after several adjustments, the park was open to the public and was a success. However, Walt Disney was not satisfied because he wanted a more complete immersion of the guest in his park.

In 1964, Walt began planning to build a much larger park than Walt Disney World in Orlando, Florida. Everything was thought for a more complete immersion of the visitors. However, Walt

\footnotetext{
2 Disponível em: https://disneyparks.disney.go.com/blog/2014/11/happy-birthday-mickey-mouse-2/
}

3Disponível em: https://www.youtube.com/watch?v=u5eHX80e9wA 
failed to live up to his project. A victim of a disease, Walt Disney died in 1966. After several years of planning and construction, Walt Disney World was opened to the public on October 1 , 1971. The first park was the Magic Kingdom, which brings together the charm of the tales fairy tale, backstage tour, classic attractions and the most famous Disney characters. The second park to be opened inside the Walt Disney World complex was Epcot in 1982, which is twice the size of the Magic Kingdom and is divided into Future World and World Showcase. The third park, inaugurated on April 22, 1998, Earth Day, is the Animal Kingdom, which is practically an amusement park on a safari. All the attractions of the park are geared towards nature and animals.

On May 27, 2017 was inaugurated at the Animal Kingdom, a brand new area for visitors of all ages, Pandora - The World of AVATAR, inspired by the Disney movie Avatar. The fourth park to be opened was Hollywood Studios on May 1, 1989, and is the smallest of the four park complexes. It is dedicated to entertainment, with live shows, high-speed rides, unique park attractions and backstage rides. In addition to these four theme parks, the Walt Disney World complex also has two water parks. One of them is Disney's Typhoon Lagoon, inaugurated in 1989, that simulates a paradisiac place that was taken by a storm. The park has a wave pool, water slides, lazy river, playground, surf lessons and even snorkelling in pools with fish, sharks and stingrays. The Typoon Lagoon undergoes yearly renovations and when it is not in operation, another water park remains open, Blizzard Beach, which opened on April 1, 1995, with numerous attractions for the whole family including Summit Plummet, considered one of the the highest and fastest water slides in the country.

In addition to all these parks, the complex has 27 hotels that are divided into Economic, Moderate, Luxury and Luxury Villas.

All of these parks and hotels are in only $1 / 3$ of the entire area purchased by Disney in Florida. . In addition to the Disney complex in Florida and the first park in California, Disney has 5 more parks around the world. The first of them, Disneyland Tokyo, was inaugurated in 1983 in Tokyo, Japan; in 1992, Disneyland Paris was inaugurated in France; in 2005 the Hong Kong Disneyland Resort opened in China, and the most recent was the Shanghai Disneyland in China, which opened in 2016.

\section{METHODOLOGICAL PROCEDURES}

The methodology can be understood, according to Minayo $(2009$ p14,15), "as the path of thought and practice in the approach to reality ... It includes the theoretical conceptions of the approach, articulating with theory, with empirical reality and with thoughts about reality. " In order to meet the objectives of the work, we used bibliographic research as part of the methodological process. As part of the methodological process, we also use exploratory research, because it is adequate to increase familiarity and knowledge about the subject.

This work has reached a sample of 142 valid answers. The research was divided into two parts: one to understand the experience of those who have visited a Disney park and another who did not visit, to understand the expectations of the respondents.

In the survey, there was a predominance of female participants, corresponding to $86 \%$ of the respondents, while the male respondents accounted for 14\% (Figure 1). 
Figure 1 - Sex of respondents

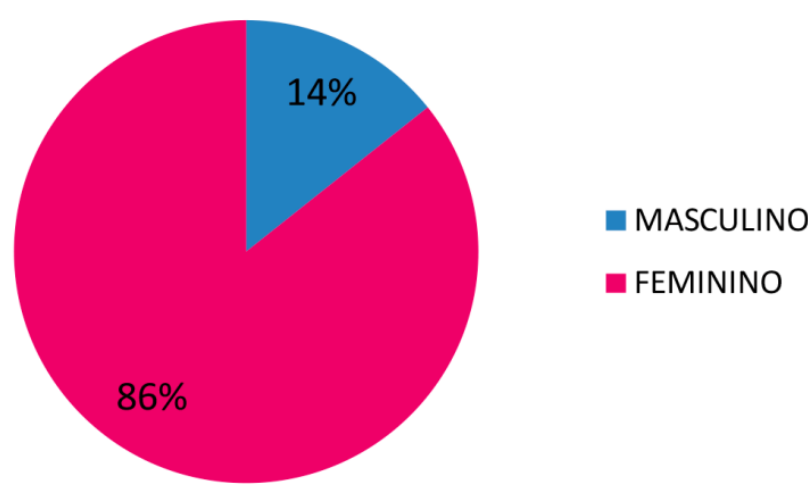

\section{Source: own elaboration}

The age group of the majority of the respondents was between 19 and 30 years old (Figure 2), corresponding to $90 \%$ of respondents, followed by $7 \%$ of respondents younger than 18 and $3 \%$ above 30 years old. According to an IBOPE survey, people aged 19 to 29 are part of the Y generation. According to Huntley (2006), the Y generation is a very consumerist generation. In addition, they consume and are loyal to brands that accompanied them in childhood, such as Disney and MC Donald's.

Figure 2: Age range of respondents

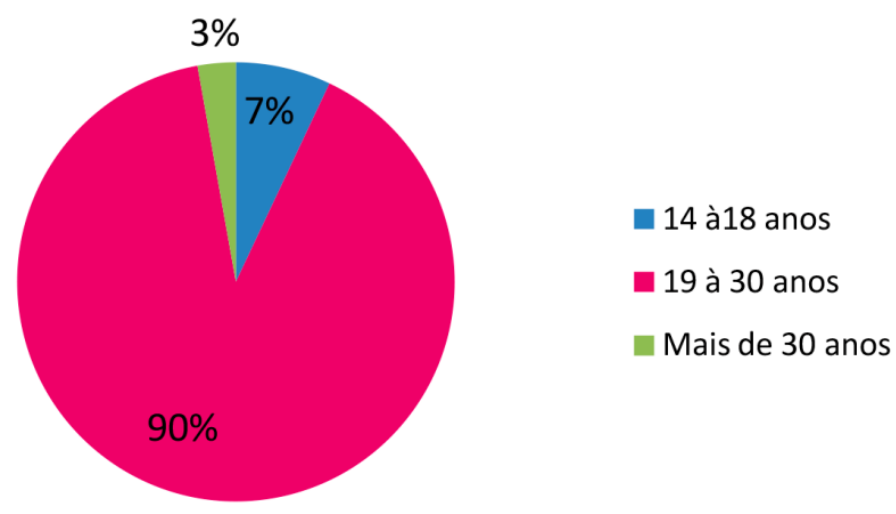

\section{Source: own elaboration}

In the questionnaire intended for those who have visited a Disney park, questions were asked regarding the experience lived by the interviewee. According to the question "Did Disney exceed your expectations?" 94\% of respondents answered "Yes" and 6\% answered "No" (Figure 3). Through this result, it is possible to realize that Disney, even charging a high value to visit the parks (approximately 99.50 USD \day) and be a long awaited destination for visitors, can exceed expectations and surprise consumers. 
Figure 3: Did Disney exceed expectations?

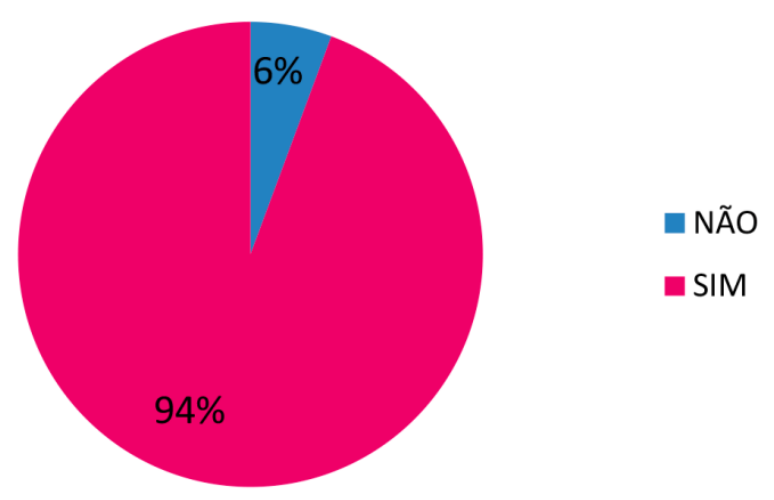

Source: own elaboration

It was observed that the service offered by Disney parks is a great differential. The vast majority of participants praise the work done by the cast members (as Disney staff are called) and some cite the term "Disney magic" in relation to attendance. In the answers, it is also possible to identify a certain degree of dissatisfaction with the waiting time of the queues, which vary according to the time of year. Disney is aware of this problem, which is a consequence of being one of the most visited parks in the world. To remedy this factor, it has been realized that Disney has strategies that, in general, are very effective.

One strategy most commented upon by interviewees is that visitors are faced with interactive games, thematic decorations, characters and entertainment throughout the queues, making the visitor distracted and queuing becomes part of the experience. Another solution to the queues is the Single Rider, a separate queue for anyone who is alone or does not mind going to some attraction with someone unknown. For example, an attraction that has a cart for 4 people and goes a family with 3 people, this 4 th place is filled by a single rider. Another very used service is the Fast Pass +, which is like a reservation in the queue. The visitor can book a time that wants to go in a particular attraction and, when arriving at the scheduled time, enters a differentiated queue and much smaller than the main queue. The service is free, however, there is a limited amount per attraction. Another highly-commented solution among the answers is the estimated waiting time in the queue at the entrance of the attraction, which allows the visitor to be able to plan and enjoy the parks better.

Overall, even if they talk a lot about waiting in the queues, most respondents said that because they are waiting differently, they do not care about how long they stay in them. This shows once again how much Disney strives to provide the best possible experience for every visitor.

"The cast members' service makes all the difference, I believe they are essential for the" magic "of Disney to happen and that everyone who visits the parks can come out with unforgettable memories. As for the queue times, I think Disney was able to mitigate the disadvantages well. It is to say that, since there is no way to extinguish the queues, Disney has created an intelligent system of forecasting time and dissemination of this information to the public, as well as implementing various activities to be done during the queue (interactive queues) "Fabiane, 21.

Of the 106 participants, 40 responded that they did not live or witnessed a differentiated experience while the rest shared moments in Disney parks. It was identified that in most of the answers, there was the presence of the cast members, who work daily with attention and courtesy to provide different moments to the visitors. From this, you can realize how much 
Disney invests in training its employees, who in turn have the authority and autonomy to use various devices to delight visitors. In Tom Connellan's book Behind the Scenes, we note the use of the term "Great attention to detail," a practice we can see in the participants' experiences through the answers, where cast members, when faced with situations like an ice cream that crashed or a balloon that burst, promptly offer a new and at no cost to the visitor. Through the answers, we also realize that Disney parks are the destination of several celebrations, ranging from birthdays to wedding requests. We can see that Disney strives to make these moments unique and special to the visitor by offering them various privileges and courtesies. "On my way to Walt Disney World to celebrate my 15th birthday we took the bottom" I'm Celebrating "and a cast member wrote" Happy Birthday, Ana "; at lunch time the attendant at the entrance to the restaurant was Brazilian and when she saw my botton asked how many years she was doing and when she said she was 15 she asked to wait a moment, the restaurant was out of breath, and spoke with the manager and along with him prepared a birthday table that had a cupcake, mini mickeys and balloons "Ana Carolina, 22. The attention to detail makes all the difference in the visitor's experience, making them feel special during the visit.

The question "Would you like to visit Disney parks? If so, why? "Was designed to understand what drives people's desire to go to Disney and the 36 respondents, 4 responded that" no "would like to go, while the rest replied" Yes "and justified. In the responses, recurring terms were identified as "dream". Most participants say going to Disney is a childhood dream. With this we can see the great power of the brand, which feeds this desire through the ages and accompanies its audience, since most respondents are in adulthood. Another reason is the desire to live the experience, because it is a place "magical", "wonderful", "fun" and "happy", showing that there is great expectation to know Disney.

It was observed that even the respondents who said they would not want to go to the parks would imagine it would be a good experience. In the responses of the interviewees, it is evident the great expectation to know the parks of Disney. Through well-crafted branding, Disney is able to get people who have never been to their parks to imagine the visit, with features that are allotted to it.

When you see the level of expectation that people go, can you compare the result of the question "Disney exceeded your expectations?" Of the survey for those who already were, resulting in $94.3 \%$ of the respondents with their expectations exceeded. With this, it is possible to confirm the great commitment and success of Disney in overcoming the high expectations of the visitors.

In both questionnaires, interviewees were asked to describe Disney in 3 words and as a result more than 100 different adjectives were obtained, the similarity between the two questionnaires was observed since two words appear in the same ones, as the most cited ones, being that the most remembered is the word "Magic", which together was quoted 85 times. Soon after the word "Fun", quoted 39 times.

In the questionnaire of anyone who has visited Disney, the words "Dream" - quoted 31 times and the word "Quality" - cited 23 times - also appear. Already in the questionnaire of who did not visit Disney, the words "Creativity" - quoted 9 times - and "Childhood" - quoted 8 times appear.

It was possible to observe that the words Magic and Fun, which stand out in the two questionnaires, are the result of the values and the image that the brand passed along the 
experience of the respondents next to it. Already the words that appear separately in each questionnaire, Dream and Quality for visitors and Creativity and Childhood for non-visitors, is due to the fact that the former has already lived the experience and have an account of what Disney was / is truly ( with the impression and opinion of it) and second to have an opinion of what the same imagines that the company offers.

\section{FINAL CONSIDERATIONS}

The development of this work allowed an analysis of how the combination of well-built branding and effective marketing experience can influence clients and prospects. To do this, we discuss the importance of marketing strategies for building and strengthening a brand. In analyzing exploratory research with customers and prospects we note that Disney strategies always have customer experience as the main focus. The fantastic attention to detail, makes your visitors have a personalized service. We can see, analyzing the research, that more than $90 \%$ of visitors had their expectations surpassed, even though they had a high level of expectation in knowing the parks.

Another factor that influences customers and prospects is the strong Disney culture, which is able to follow from children, who consume Disney products, to adulthood. This public continues to follow the brand with fidelity, since $90 \%$ of respondents were people aged between 19 and 30 years.

With a branding that is well aligned with brand values, even those who have not yet had the opportunity to go to one of the parks, can make an allusion to what Disney offers, bringing much expectation to live the experience.

Finally, it is expected that the present work will contribute as a research source to students and professionals in the field of communication, who are interested in using experience marketing as a marketing strategy, guiding them to follow examples such as The Walt Disney Company. It is also believed that it can serve as the basis for new entrepreneurs, pointing the focus on the client as a key point.

\section{References}

CHANNEL, History. Modern Wonders: The World of Walt Disney. Available at:

<https://www.youtube.com/watch?v=u5eHX80e9wA\&t=530s> Accessed on 27 Jun. 2018

DAVID AAKER. On Branding: 20 principles that determine brand success. 1 ed. Porto Alegre: Bookman Editora LTDA, 2015.

DISNEY GUIDE. History of Disney. Available at: <http://www.disneyguia.com.br/site/historia-da-disney/> Accessed on June 162018

DISNEY INSTITUTE. The Disney way to charm customers. 1. ed. São Paulo: Editora Saraiva, 2011.

DISNEYLAND PARIS. Available at: <http://www.disneylandparis.com/en/> Accessed on: 17 June 2018.

DISNEY PARKS BLOG. Fifteen Fun Facts For Mickey Mouse's Birthday. Available at:

<https://disneyparks.disney.go.com/blog/2014/11/happy-birthday-mickey-mouse-2/> Accessed on June 16 2018.

EISNER, Michael. The Disney Way to delight customers. From exceptional service to never stop growing and believing. 4. ed. São Paulo: Editora Saraiva, 2011. p.20.

FEDERICO GROSSO. The era of the (incredible) customer experience, 2016. Available at:

<http://www.meioemensagem.com.br/home/opiniao/2016/08/19/a-era-da-incrivel-experiencia-doclient.html> Access on June 16. 2018.

FRANCISCO ANTONIO SERRALVO and MÁRCIO TADEU FURRIER. Fundamentals of brand positioning: a theoretical review. AVAILABLE IN 
<http://sistema.semead.com.br/7semead/paginas/artigos\%20recebidos/marketing/MKT65_-

_Position_of_marcas.PDF> Accessed on: Jun 10. 2018.

STUDENT'S GUIDE. The creation of Mickey Mouse. Available at:

<http://origin.guiadoestudante.abril.com.br/aventuras-historia/criacao-mickey-mouse-479490.shtml> Accessed on June 16. 2018.

HUNTLEY, Rebecca. The World according to Y: Inside the new adult generation. Sydney: McPherson's Printing Group, 2006.

JEAN COSTA. Birth and evolution of the brand in 7 steps, 2013. Available in:

<https://foroalfa.org/articulos/nascimento-e-evolucao-da-marca-em-7-passos> Accessed on: 01 Jun. 2018

KEVIN LANE KELLER AND MARCOS MACHADO. Strategic Brand Management. 3 ed. São Paulo: Pearsol Education do Brasil 2006.

KOTLER, Philip. Marketing administration: the new millennium edition. São Paulo: Prentice Hall, 2010.

MARCOS HILLER. Branding: the art of brand building. São Paulo: Trevisan Editora, 2012.

MARKET REALIST. Disney's Theme Parks Are Riding High: Here's Why. Available at: <http://marketrealist.com/2017/06/disneys-theme-parks-are-riding-high-heres-why/> Accessed on 01 July 2018.

MARILIA GOMES AND GLAURA KURY. The Evolution of Marketing for Marketing 3.0: The Marketing of Cause. 11p. Monography (Bachelor). Advertising and marketing. University of Fortaleza (UNIFOR). Fortaleza, 2013. Available at: <http://www.portalintercom.org.br/anais/nordeste2013/resumos/R37-0945-1.pdf> Accessed on: May 25, 2018

BEST DESTINATIONS. Disney's Typhoon Lagoon. Available at: <https://guia.melhoresdestinos.com.br/disney-styphoon-lagoon-73-1760-p.html> Accessed on June 17, 2018.

MIKROMARKT. Positioning Chapter 5: Product Differentiation. Available at: <http://www.mikromarkt.eu/pdfs/en_modul_1_5.pdf> Accessed on: 10 Jun. 2018.

THE GLOBE. Disney's Shanghai is inaugurated, hoping to be the most visited park in the world. Available at: $<$ https://oglobo.globo.com/boa-viagem/disney-de-xangai-inaugurada-com-expectativa-de-ser-parque-maisvisitado-do-mundo-19518983> Accessed on: 18 of June 2018.

PHILIP KOTLER, HERMAWAN KARTAJAYA and IWAN SETIAWAN. Marketing 3.0: The forces that are defining the new marketing centered on the human being. 1 ed. Rio de Janeiro: Elsevier Editora Ltda, 2010. Preface written by Susilo BamBang Yudhoyono.

PHILIP KOTLER. Marketing from A to Z. 1 ed. Rio de Janeiro: Elsevier Editora Ltda, 2003.

THE WALT DISNEY COMPANY. Available at: <thewaltdisneycompany.com> Accessed on: 01 July 2018.

WALT DISNEY WORLD. Thematic parks. Available in: <http://disneyworld.disney.go.com/en-us/parks/> Accessed on: Jun 16, 2018. 